\title{
Avaliação da produtividade do centro cirúrgico de um hospital universitário sob a ótica do lean healthcare
}

\section{Evaluation of the productivity of the surgical center of a university hospital from the perspective of lean healthcare}

\author{
Rosely Costa da Silva Bandeira \\ Universidade Federal do Amazonas - UFAM - Brasil \\ roselycs1@gmail.com \\ ORCID: https://orcid.org/0000-0002-7101-1669 \\ Armando Araújo de Souza Júnior \\ Universidade Federal do Amazonas - UFAM - Brasil \\ armandoaraujo@ufam.edu.br \\ ORCID: https://orcid.org/0000-0003-2950-1434 \\ Sandy Rebelo Bandeira \\ I Universidade Federal do Amazonas - UFAM - Brasil \\ bandeira.san@gmail.com \\ ORCID: https://orcid.org/0000-0002-2356-9780
}

\section{Resumo}

Objetivo: Este estudo tem por objetivo apresentar uma proposta para avaliar o desempenho do Centro Cirúrgico de um Hospital Universitário baseada no Overall Equipment Effectiveness - OEE. Nesse sentido, busca-se avaliar a eficiência do setor identificando os fatores limitantes aos processos de cirurgia. Metodologia: Trata-se de uma pesquisa aplicada, cujos procedimentos adotados foram o estudo de caso, a pesquisa participante e a pesquisa-ação. Para a coleta de dados, utilizou-se de pesquisa documental, entrevistas do tipo não-estruturadas e da elaboração de Mapa de Fluxo de Valor (MFV). Principais resultados: As avaliações mostraram desempenhos abaixo do ideal para o indicador de Disponibilidade. Constatou-se que o percentual de espera é muito grande em relação ao tempo de cirurgia, o que acaba ocultando a real capacidade do centro cirúrgico. Os resultados obtidos no indicador Desempenho destacam os cancelamentos como fatores de impacto na produtividade. 0 índice de eficiência encontrado para o setor foi baixo em relação ao indicador de classe mundial. Contribuições: 0 estudo do uso de indicadores contribui com a teoria, uma vez que os pressupostos da administração podem ser empregados nas mais diversas áreas, inclusive hospitalares. Na prática, o estudo corrobora com a parte operacional ao qualificar o planejamento do centro cirúrgico, possibilitando aos gestores uma otimização dos tempos, o que impacta em importantes ganhos à sociedade.

Palavras-chave: Lean healthcare; avaliação; eficiência produtiva; centro cirúrgico

\begin{abstract}
Purpose: This study aims to present a proposal to evaluate the performance of the Surgical Center of a University Hospital based on the OEE. In this sense, we seek to assess the efficiency of the sector by identifying the limiting factors to the surgery processes. Methodology: It is an applied research, whose adopted procedures were the case study, the participant research and the action research. For data collection, documentary research, unstructured interviews and the elaboration of a Value Flow Map (MFV) were used. Main results: The evaluations showed performances below the ideal for the Availability indicator. It was found that the waiting percentage is very large in relation to the time of surgery, which ends up hiding the real capacity of the operating room. The results obtained in the Performance indicator highlight cancellations as factors that impact productivity. The efficiency index found for the sector was low in relation to the world class indicator. Contributions: The study of the use of indicators contributes to the theory, since the assumptions of the administration can be used in the most diverse areas, including hospitals. In practice, the study corroborates the operational part by qualifying the planning of the surgical center, allowing managers to optimize times, which impacts on important gains for society.
\end{abstract}

Keywords: Lean healthcare; assessment; productive efficiency; surgery center 


\section{Introdução}

Ao longo dos anos, tanto os indivíduos quanto as organizações têm procurado mensurar e analisar o seu próprio desempenho sob os mais diversos aspectos. No meio empresarial, a utilização de indicadores tem sido amplamente empregada com a introdução de métodos de avaliação da produtividade, revelando assim, o sucesso ou fracasso das empresas (Rocha \& Gonçalves, 2018; Da Silva et al., 2019).

Notadamente, a questão da produtividade é um tema preocupante no cenário de qualquer nível organizacional, uma vez que as companhias se veem obrigadas a acompanhar as diversas transformações e exigências de um mercado cada dia mais dinâmico, o que acaba forçando as empresas a mudarem suas práticas (Silva \& Borsato, 2017; Klemann et al., 2020).

Tais mudanças decorrentes da alta competitividade fazem com que as empresas fujam dos antigos padrões e repensem seus conceitos de gestão. A introdução de novas práticas que auxiliam no desenvolvimento dos trabalhos associada a uma visão sistêmica das atividades têm sido uma das adaptações implementadas (Lacerda, Xambre \& Alvelos, 2016; Da Silva et al., 2019).

Ressalta-se que a preocupação com a produtividade não é algo recente, já no século XX estudos voltados aos processos de produção apresentavam a relação entre o que foi produzido e o recurso empregado na produção, demonstrando interesse em difundir o resultado das atividades desenvolvidas, e como poderiam ser melhoradas de forma a alcançar vantagem competitiva (Rocha \& Gonçalves, 2018).

Como em qualquer outro setor da economia, os hospitais, conhecidos por sua complexidade e intensos serviços na área da saúde, têm por desafio serem produtivos e eficientes no atendimento à vida humana (Souza, Scatena \& Kehrig, 2016; Tortorella, Van Dun \& De Almeida, 2019).

Nessa ótica, Bittar (1996) esclarece que devido à multiplicidade de tarefas desempenhadas em um hospital e a consequente complexidade de sua natureza, a aplicação de indicadores únicos para mensurar a produtividade se torna um problema. Por outro lado, quando combinados, o monitoramento por meio de indicadores coopera consideravelmente para a melhoria da produtividade dos serviços de saúde, bem como para qualidade e o controle dos custos (Vignochi, Gonçalo \& Lezana, 2014).

Consideram-se estudos como o de Bittar (1996), colocando sob análise a produtividade em hospitais a partir de alguns indicadores hospitalares, onde puderam concluir que hospitais que utilizam adequadamente seus recursos humanos, materiais e financeiros são os que apresentam maior produtividade.

Vignochi, Gonçalo e Lezana (2014), por sua vez, buscaram analisar como os gestores dos hospitais utilizam os indicadores para mensurar seus desempenhos, apresentando dentre os resultados alcançados, que o uso de indicadores gera evidências traduzidas em conhecimento, e que se melhor compartilhados, melhoram o desempenho de grupos hospitalares.

Destaca-se a importância de se analisar os ambientes hospitalares de modo a compreender e avaliar como os processos são desempenhados e qual o nível de produtividade alcançado por suas unidades. Nesse viés, este estudo tem por objetivo geral apresentar uma proposta para avaliar o desempenho do Centro Cirúrgico de um Hospital Universitário baseada no método Overall Equipment Effectiveness - OEE.

0 artigo divide-se em 5 partes: Após a introdução, o referencial teórico aborda o Lean Healthcare e sua contribuição literária às práticas enxutas, sobre o Mapeamento de Fluxo de valor como técnica bastante utilizada, inclusive na área da saúde, e sobre a importância e uso dos indicadores de desempenho nos processos. 0 terceiro tópico descreve a metodologia da pesquisa e a análise dos dados coletados. Em seguida são apresentados os resultados da aplicação do método baseado no $O E E$, as sugestões de melhoria e as constribuições do estudo. Por último, são delianeadas as considerações finais.

\section{Referencial teórico}

\subsection{Lean healthcare}

O setor da saúde, por sua complexidade, é constantemente confrontado com problemas relacionados a custos elevados. Pensando nisso, o gerenciamento Lean encontrou meios de trabalhar nesta importante área focando na eficiência e satisfação do paciente (Hallam \& Contreras, 2018; Tlapa et al., 2020; Alkaabi et al., 2020).

0 Lean Healthcare se destaca como uma filosofia de gestão que adiciona uma cultura aos hospitais com base no aumento da satisfação de pacientes e demais envolvidos com o implemento de 
aperfeiçoamentos contínuos, nos quais, os funcionários também colaboram identificando e eliminando aquilo que não agrega valor (Sing, 2019; Tortorella, Van Dun \& De Almeida, 2019; Tlapa et al., 2020).

A proposta de sua utilização tem como objetivos principais a melhoria na assistência prestada ao paciente e redução tanto no tempo de espera para atendimento, quanto no tempo de permanência de pacientes nos ambientes hospitalares (Hallam \& Contreras, 2018).

Considerando a essência da filosofia Lean, o Lean Healthcare implementa técnicas e ferramentas com vistas a eliminar os desperdícios de produção. A Figura 1 apresenta os sete desperdícios originalmente propostos por Taiichi Ohno, adaptados ao Lean Healthcare.

\section{Figura 1: Os sete desperdícios adaptados ao Lean Healthcare}

\begin{tabular}{|c|c|c|}
\hline Tipo de desperdício & Descrição & Adaptado ao Lean Healthcare \\
\hline Defeitos & $\begin{array}{l}\text { Problemas de qualidade durante os processos que exigem } \\
\text { retrabalhos. Estão relacionados a falta de padronização ou } \\
\text { de sistemas de controle da produção. }\end{array}$ & Erros médicos. \\
\hline Tempo de espera & $\begin{array}{c}\text { Toda pausa durante o processo de produção de um produto, } \\
\text { seja por falta de pessoas, materiais ou equipamentos, } \\
\text { significa valor não agregado para o cliente. }\end{array}$ & $\begin{array}{l}\text { A espera dos enfermos por } \\
\text { atendimentos profissionais, prescrição } \\
\text { médica, ou resultados de exames. }\end{array}$ \\
\hline Inventário & $\begin{array}{c}\text { Matéria-prima esperando para ser processada. Muitas vezes } \\
\text { o estoque de produtos ou materiais está associado a } \\
\text { gargalos na produção. }\end{array}$ & Estoque excessivo de medicamentos. \\
\hline Movimentação & $\begin{array}{c}\text { O movimento desnecessário de trabalhadores, máquinas ou } \\
\text { ferramentas retardam a execução e não agregam valor ao } \\
\text { produto. }\end{array}$ & $\begin{array}{l}\text { Movimentos desnecessários de pessoas } \\
\text { que procuram por informações ou } \\
\text { documentos. }\end{array}$ \\
\hline Processamento & $\begin{array}{l}\text { Toda operação ou etapa de um processo que não contribua } \\
\text { para gerar valor ao produto é considerada um desperdício } \\
\text { de produção. }\end{array}$ & $\begin{array}{l}\text { Processamento excessivo com } \\
\text { Formulários desnecessários. }\end{array}$ \\
\hline Excesso de Produção & $\begin{array}{l}\text { Produzir mais do que a demanda do momento acarreta no } \\
\text { uso desnecessário dos recursos sem um retorno financeiro, } \\
\text { além de gerar muito estoque. }\end{array}$ & $\begin{array}{c}\text { Realizar investigações médicas } \\
\text { desnecessárias. }\end{array}$ \\
\hline Transporte & $\begin{array}{l}\text { Um produto ou material transportado de um lado para o } \\
\text { outro dentro da fábrica não está sendo processado, por isso, } \\
\text { não agrega valor ao cliente. Além dos custos do próprio } \\
\text { equipamento de transporte e manutenções. }\end{array}$ & $\begin{array}{l}\text { De pacientes, amostras ou materiais } \\
\text { hospitalares. }\end{array}$ \\
\hline
\end{tabular}

Fonte: Adaptado de Zakaria et al. (2017); Hallam \& Contreras (2018)

As melhores práticas advindas do Lean Healthcare podem favorecer a melhora dos processos de saúde, uma vez que o método foca no paciente, na eliminação do desperdício, na identificação de gargalos, redução de custos e melhoria contínua (Costa \& Godinho Filho, 2016; Fitria, Dery \& Prassetiyo, 2019).

\subsection{Mapeamento de fluxo de valor}

Nos últimos anos, as organizações têm procurado fugir dos padrões ultrapassados mudando seus conceitos de gestão, adotando uma visão mais holística, e introduzindo novas práticas que auxiliem seus modelos de trabalho que contribuam com a redução dos custos (Lacerda, Xambre \& Alvelos, 2016; Stadnicka, 2019).

Um desses métodos é o Value Stream Mapping (VSM) ou Mapeamento de Fluxo de Valor (MFV), que consiste em uma técnica de mapear todas as atividades da produção descrevendo por imagem o seu estado atual (Zahrotun \& Taufiq, 2018; Vilventhan, Ram \& Sugumaran, 2019).

Esse mapa permite visualizar o que acontece durante os trabalhos, também documenta, analisa e aprimora fluxos, além de conhecer o tempo das tarefas, e o que agrega ou não valor a clientela (Alkaabi et al., 2020).

Zahrotun e Taufiq (2018) afirmam que o método se baseia no mapeamento e análise da linha produtiva, com vistas a entender o fluxo tanto de informações quanto de processos existentes, com o objetivo de aperfeiçoar não apenas trabalhos isolados, mas o processo por completo.

Trata-se de um método visual como um diagrama que detalha as fases de um trabalho, de modo a simplificar o entendimento dos sistemas de produção, e que possibilita que as empresas remodelem seus processos (Ramaswamy et al., 2017; Zeferino et al., 2019).

Como objetivo, de acordo com o entendimento de Suarez-Barraza, Miguel-Davila e VasquezGarcía (2016), o mapeamento de fluxo de valor traz a proposta de fortalecer os processos com atividades que realmente agreguem valor. Além de fornecer saídas aos processos produtivos tais como menores custos, resposta célere ao cliente e maior qualidades dos produtos (Lacerda, Xambre \& Alvelos, 2016). 
Tendo em vista o uso de símbolos para a elaboração dos mapas, o Quadro 1 apresenta alguns destes ícones utilizados no MFV representando o fluxo de materiais e informações.

\section{Quadro 1 - Simbologia do MFV}

\begin{tabular}{|c|c|c|}
\hline Símbolo & Significado & Definição \\
\hline & Processo & $\begin{array}{l}\text { Indica um processo de produção, uma área de fluxo } \\
\text { contínuo. }\end{array}$ \\
\hline 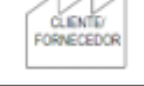 & Fontes externas & $\begin{array}{l}\text { Identifica clientes (acima, no canto direito) e } \\
\text { fornecedores (canto superior esquerdo). }\end{array}$ \\
\hline iocens & Estoque & $\begin{array}{l}\text { Representa lugares onde o estoque se acumula ou } \\
\text { onde o fluxo está parando. }\end{array}$ \\
\hline momp & $\begin{array}{l}\text { Movimento de material } \\
\text { empurrado }\end{array}$ & $\begin{array}{l}\text { Identifica a tranferência de material de um } \\
\text { processo para o seguinte de forma empurrada. }\end{array}$ \\
\hline$\frac{\cos }{\cos }$ & Necessidade de Kaizen & $\begin{array}{l}\text { Utilizado para registrar melhorias necessárias aos } \\
\text { processos e equipamentos. }\end{array}$ \\
\hline 4 & Fluxo de informação manual & Fluxo de informações por papel. \\
\hline 4 & Fluxo de informação eletrônica & $\begin{array}{l}\text { Utilizada quando a informação flui via troca } \\
\text { eletrônica de dados. }\end{array}$ \\
\hline
\end{tabular}

Fonte: Rother e Shook (2003)

\subsection{Importância do uso de indicadores em centros cirúrgicos}

A utilização de indicadores é importante na geração de conhecimento, principalmente ao transformar as informações em evidências que vão orientar positivamente as ações estratégicas das organizações hospitalares; aumentar a produtividade, e consequentemente, vão melhorar seu indicador de qualidade: a satisfação dos usuários (Rocha \& Gonçalves, 2018; Barrios et al., 2020).

Indicadores são instrumentos de medição qualitativa ou quantitativa, que evidenciam transparência e definem parâmetros para representar o estado de uma situação ou processo, sendo a base para a tomada de decisão uma vez que fornecem informações de monitoramento e avaliação aos atos de gestão (Miname et al., 2017; Francischini \& Francischini, 2018).

$\mathrm{Na}$ área hospitalar, os baixos índices de eficiência em centros cirúrgicos se relacionam sobretudo: a variedade de problemas dos pacientes; às variáveis quanto ao tipo de intervenção; e aos fatores imprevisíveis que podem ocorrer ao longo das intervenções cirúrgicas (Cima et al., 2011; Guimarães, 2018).

Fatores ligados ao tempo das operações também são causas de ineficiência nos centros cirúrgicos como: cancelamentos, falta de planejamento cirúrgicos, falta de planejamento no preparo das salas e no tempo de limpeza. Desta feita, faz-se necessário conhecer o desempenho atual para traçar melhorias na eficiência das cirurgias, sobretudo, com a redução dos tempos operacionais (Guimarães, 2018).

\subsection{OEE (Overall Equipment Effectiveness)}

O método OEE (ou Eficácia Geral do Equipamento) é um indicador global de eficiência comumente utilizado para medir e maximizar a eficácia de equipamentos individuais ou processos inteiros, baseado em 3 categorias: Taxa de Disponibilidade, Taxa de Desempenho e Taxa de Qualidade (Saleem et al., 2017; Tsarouhas, 2019).

Saleem et al. (2017), descrevem o indicador Disponibilidade como aquele que leva em consideração o tempo de indisponibilidade do equipamento devido a falhas, ajustes de configuração ou paradas para setup.

O Desempenho ou Perfomance é aquele que considera as perdas de velocidade ocasionadas por pequenas paradas e lentidão do equipamento. Já o indicador Qualidade apresenta a relação entre peças boas produzidas e o total de peças produzidas (Saleem et al., 2017).

Como ilustra a Figura 2, o OEE foi desenvolvido, basicamente, a partir das 6 grandes perdas ligadas ao indicadores que o compõe. Assim, sua utilização auxilia no aumento da produtividade dos equipamentos à medida em que mede oportunidades de melhoria na Disponibilidade, Desempenho e 
na Qualidade, evidenciando as perdas causadoras de impacto (Negro, Do Prado \& Antunes Neto, 2020).

Figura 2: OEE e suas perdas principais

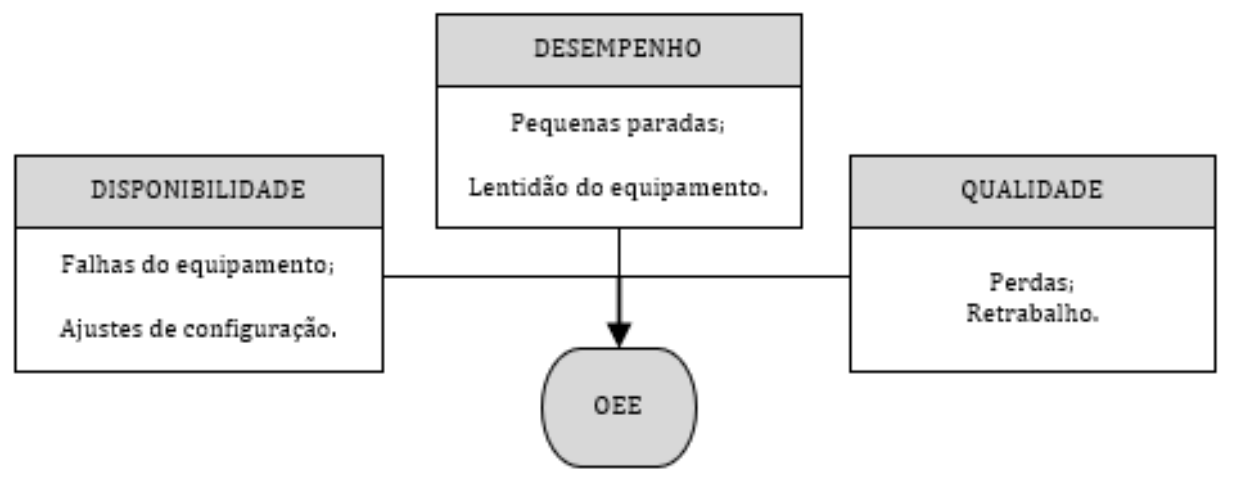

Fonte: Elaborado pelos autores (2021)

Ainda para Negro, Do Prado \& Antunes Neto (2020), tal sistemática de medição expõe, por meio de cálculos, as causas das paradas de produção bem como as perdas de desempenho e qualidade nas organizações. Por isso, é considerado um relevante indicador para identificação de falhas e auxílio à tomada de decisão.

O uso do OEE se justifica pela relevância de analisar o estado real da utilização dos recursos de equipamentos/ linhas de produção (Toledo, Ferrão \& da Costa Cruz, 2019) no tocante: a quanto o setor/equipe está disponível para a produção (baseado em dados de estrutura física e horas disponíveis de trabalho), calculado por meio do indicador de Disponibilidade; ao conhecimento de sua performance produtiva atual frente aos recursos dispostos (indicador de Desempenho); e qual o índice de Qualidade do produto ofertado.

\section{Método}

Esta pesquisa caracteriza-se como aplicada, de caráter exploratório e descritivo, com a adoção de métodos mistos (qualitativos e quantitativos), cujo objetivo foi apresentar uma proposta para avaliar o desempenho do Centro Cirúrgico de um Hospital Universitário baseada no OEE. Os métodos utilizados para alcançar tal objetivo foram o estudo de caso, a pesquisa participante e a pesquisa-ação.

0 estudo de caso investiga um evento atual em seu ambiente natural, onde é proporcionada ao observador a possibilidade de enxergar os fenômenos de maneira real e extensiva para então descrevêlos ou explicá-los (Yin, 2015; Severino, 2017). Assim, o lócus da pesquisa foi o Centro Cirúrgico de um Hospital Universitário de médio porte.

Na pesquisa participante o pesquisador compartilha a experiência dos indivíduos pesquisados, interagindo com eles durante a observação dos acontecimentos (Severino, 2017). Por isso, houve interação direta com a chefe do centro cirúrgico e alguns técnicos / enfermeiros durante a pesquisa.

Já o método da pesquisa-ação é aquele realizado de forma colaborativa e ativa, entre o observador e os observados (Cooper \& Schindler, 2016; Rocha, 2019). Assim, o procedimento adotado foi observar as especificidades dos processos do centro cirúrgico na intenção de colaborar, por meio da pesquisa, com a gestão do setor.

$\mathrm{Na}$ etapa da coleta de dados, primeiramente foi utilizada a Pesquisa Documental. Qualquer documento pode ser usado como fonte de informação (Prodanov \& Freitas, 2013). Assim, a pesquisa documental levantou dados em relatórios, manuais e livros de registros manuais com particularidades da prática do centro cirúrgico. A abrangência da pesquisa documental considerou documentos do período de julho a dezembro de 2019.

No segundo momento, entre os meses de setembro e outubro de 2020, foram realizadas entrevistas do tipo não-estruturadas com o objetivo de colher o máximo de informações possível. 0 uso da entrevista se caracteriza pela comunicação entre o pesquisador e o pesquisado, neste caso, o informante, a fim de que questões objetos da pesquisa sejam esclarecidas (Chizzotti, 2018). Destaca-se que as entrevistas foram direcionadas, unicamente, ao entendimento dos processos desenvolvidos no centro cirúrgico como: planejamento e execução das cirurgias, do conhecimento dos turnos de trabalho, da equipe de profissionais (em números) e das salas de cirurgias disponíveis.

Durante a realização das entrevistas, a maior parte das informações foram obtidas com a chefe do centro cirúrgico. Enfermeiros e técnicos colaboraram em momentos distintos, ratificando e complementando as informações anteriormente dadas.

Na terceira fase, considerando as informações já coletadas, foi produzido o Mapa de Fluxo de 
Valor ilustrando o estado atual da produção no centro cirúrgico, no intuito de melhor visualizar o processo e propor melhorias.

A primeira análise foi resultado do levantamento documental. Tendo essa base, as informações sobre as principais atividades do centro cirúrgico subsidiaram a elaboração de planilhas e quadros. Já as informações obtidas nas entrevistas não-estruturadas foram dispostas em aplicativos de processamento de texto, como a Microsoft Office Word, e auxiliaram na construção do mapa de fluxo de valor. Para a representação visual e criação do estado atual, foi utilizado o software Microsoft Visio.

Como última etapa, para análise da eficiência do centro cirúrgico, considerando a avaliação de indicadores e produtividade, foi utilizado uma metodologia baseada no método OEE denominada Operating Room Effectiveness (ORE). O ORE utiliza a base metodológica do OEE e busca identificar a utilização real dos equipamentos das salas de cirurgias, mensurando a eficiência destes instrumentos. Assim, considerando dados atuais do setor, foram elaboradas planilhas de cálculo para identificar quanto dos recursos disponíveis estão sendo utilizados, qual o desempenho do centro cirúrgico frente ao seu planejamento, e qual a qualidade dos serviços, neste caso, a qualidade das cirurgias realizadas.

Durante a pesquisa não foram encontrados indicadores que interpretassem em detalhes o desempenho da equipe cirúrgica em cada mês, por isso, para esta pesquisa, foram levantados os livros de registros com informações de cada cirurgia, seus respectivos tempos de início e fim, e outros.

A pesquisa de campo ocorreu entre setembro de 2020 a janeiro de 2021 (período este que abrangeu as demais etapas da pesquisa) e, de modo a conhecer a eficiência do centro cirúrgico, foram coletados dados considerando o período de 6 meses: julho a dezembro de 2019. 0 ano de 2020, por ser atípico, não foi objeto de estudo, pois, conforme relatos dos colaboradores, a pandemia inviabilizou drasticamente a realização de cirurgias, o que justificou a escolha do período de coleta dos dados supramencionado.

\section{Resultados}

A partir dos registros manuais de cirurgia, foi elaborada uma base de dados eletrônica com cada procedimento cirúrgico realizado no período pesquisado.

\section{Figura 3 - Base de dados de registro de cirurgias}

\begin{tabular}{|c|c|c|c|c|c|c|}
\hline \multicolumn{7}{|c|}{ REGISTRO DE CIRURGIAS (ELETIVAS e URGÊNCIA) - 2019} \\
\hline${ }^{\text {DATA }}$ & SALA MONTADA & $\begin{array}{l}\text { INÍ́CIO DA } \\
\text { CIRURGIA }\end{array}$ & TÉRMINO & TEMPO DE ESPERA & DURAÇÃOO DA CIRURGIA & $\begin{array}{l}\text { SAÍDA DA SALA } \\
\text { DE OPERAÇÃO }\end{array}$ \\
\hline $01 /$ jul & 09:22 & 09:33 & $09: 45$ & $00: 11$ & $00: 12$ & \begin{tabular}{|r|}
$09: 50$ \\
\end{tabular} \\
\hline $01 / \mathrm{jul}$ & $07: 25$ & 08:15 & $10: 45$ & 00:50 & $02: 30$ & 11:00 \\
\hline $01 / \mathrm{jul}$ & $07: 10$ & $08: 10$ & $12: 10$ & $01: 00$ & 04:00 & $12: 45$ \\
\hline $01 / \mathrm{jul}$ & $08: 00$ & $09: 20$ & $12: 35$ & $01: 20$ & 03:15 & 12:50 \\
\hline $01 / \mathrm{jul}$ & 13:00 & 13:50 & $14: 30$ & $00: 50$ & $00: 40$ & $14: 40$ \\
\hline $01 / \mathrm{jul}$ & $15: 00$ & $15: 38$ & $16: 11$ & $00: 38$ & $00: 33$ & $16: 15$ \\
\hline $01 / \mathrm{jul}$ & $13: 30$ & $15: 00$ & $15: 35$ & $01: 30$ & $00: 35$ & $15: 45$ \\
\hline $01 / \mathrm{jul}$ & $08: 35$ & $10: 25$ & $14: 00$ & $01: 50$ & 03:35 & $14: 34$ \\
\hline $01 / \mathrm{jul}$ & $07: 30$ & $08: 37$ & $10: 00$ & 01:07 & $01: 23$ & $10: 22$ \\
\hline $02 / \mathrm{jul}$ & $06: 50$ & $08: 15$ & $10: 30$ & $01: 25$ & 02:15 & $10: 50$ \\
\hline $02 / \mathrm{jul}$ & $06: 00$ & 09:00 & 11:00 & 03:00 & 02:00 & 11:30 \\
\hline $02 / \mathrm{jul}$ & $13: 15$ & $13: 25$ & $13: 35$ & $00: 10$ & $00: 10$ & $13: 38$ \\
\hline $02 / \mathrm{jul}$ & 13:50 & $14: 55$ & $19: 40$ & $01: 05$ & $04: 45$ & 19:50 \\
\hline $02 / \mathrm{jul}$ & $12: 30$ & $14: 40$ & $17: 50$ & $02: 10$ & $03: 10$ & $18: 20$ \\
\hline $02 / \mathrm{jul}$ & $14: 50$ & $16: 33$ & $18: 22$ & $01: 43$ & $01: 49$ & $18: 36$ \\
\hline $03 / \mathrm{jul}$ & $07: 35$ & $08: 30$ & $12: 00$ & $00: 55$ & 03:30 & $12: 15$ \\
\hline $03 / \mathrm{jul}$ & $07: 40$ & $08: 50$ & $10: 00$ & $01: 10$ & $01: 10$ & $10: 55$ \\
\hline $03 / \mathrm{jul}$ & $07: 00$ & 09:00 & $11: 30$ & $02: 00$ & $02: 30$ & $11: 45$ \\
\hline $03 / \mathrm{jul}$ & $12: 55$ & $13: 20$ & $13: 40$ & $00: 25$ & $00: 20$ & 13:50 \\
\hline $03 / \mathrm{jul}$ & $09: 20$ & $10: 47$ & 11:12 & $01: 27$ & $00: 25$ & $11: 15$ \\
\hline $03 / \mathrm{jul}$ & $10: 20$ & $11: 15$ & $11: 45$ & $00: 55$ & $00: 30$ & $11: 50$ \\
\hline $03 / \mathrm{jul}$ & $12: 10$ & $12: 35$ & 13:00 & $00: 25$ & $00: 25$ & $13: 15$ \\
\hline $03 / \mathrm{jul}$ & $11: 00$ & $12: 25$ & $13: 45$ & $01: 25$ & $01: 20$ & 14:09 \\
\hline $03 / \mathrm{jul}$ & $13: 20$ & 14:50 & $15: 25$ & $01: 30$ & 00:35 & $15: 30$ \\
\hline $03 / \mathrm{jul}$ & 13:00 & $14: 14$ & $16: 13$ & 01:14 & 01:59 & $16: 30$ \\
\hline $03 / \mathrm{jul}$ & $11: 25$ & $13: 20$ & $16: 30$ & $01: 55$ & 03:10 & $16: 35$ \\
\hline $03 / \mathrm{jul}$ & 12:00 & $12: 30$ & $12: 45$ & $00: 30$ & 00:15 & 12:50 \\
\hline $03 / \mathrm{jul}$ & $11: 40$ & 12:17 & 12:50 & $00: 37$ & 00:33 & 12:55 \\
\hline $03 / \mathrm{jul}$ & $14: 00$ & $15: 15$ & $17: 25$ & 01:15 & 02:10 & $17: 45$ \\
\hline JUL19 & AGO19 & OUT19 & DEZ1S & ๑ & & \\
\hline
\end{tabular}

Fonte: Dados da pesquisa (2021)

Os dados da Figura 3 correspondem ao mês de julho de 2019, e mostram a "Data" que a cirurgia ocorreu; a hora da "Sala Montada", como o momento em que a sala estava pronta para a cirurgia; o "Início e Término da cirurgia" (em horas), bem como a hora da "Saída do paciente da Sala de Operação".

Outras colunas foram acrescentadas posteriormente, demonstrando o momento em que os dados já estavam sendo manipulados para análise e mensuração de tempos. A coluna "Tempo de Espera" representa o tempo entre a hora em que a sala estava pronta para a cirurgia e quando ela 
iniciou, já a coluna "Duração da Cirurgia" representa de fato o tempo de execução dos procedimentos.

Por meio da base de dados, cada mês foi analisado individualmente, e assim, foi possível evidenciar alguns resultados. Salienta-se que o centro cirúrgico do hospital trabalha $24 \mathrm{~h} /$ dia, manhã, tarde e noite, observando o tempo disponível de toda a equipe de profissionais (médicos, enfermeiros e anestesistas).

$\mathrm{Na}$ análise inicial da planilha "registro de cirurgias", ficou demonstrado que a maioria das cirurgias foram realizadas no $1^{\mathrm{o}}$ turno do dia, ou seja, aquelas iniciadas entre às $7 \mathrm{~h}$ e $13 \mathrm{~h}$.

Tabela 1 - Cirurgias realizadas por turno

\begin{tabular}{|c|c|c|c|c|c|c|c|c|c|c|c|c|}
\hline \multirow{2}{*}{$\begin{array}{l}\text { Cirurgias } \\
\text { Iniciadas }\end{array}$} & \multicolumn{2}{|c|}{ Jul/19 } & \multicolumn{2}{|c|}{ Ago/19 } & \multicolumn{2}{|c|}{ Set/19 } & \multicolumn{2}{|c|}{ Out/19 } & \multicolumn{2}{|c|}{ Nov/19 } & \multicolumn{2}{|c|}{ Dez/19 } \\
\hline & no & $\%$ & no & $\%$ & no & $\%$ & no & $\%$ & no & $\%$ & no & $\%$ \\
\hline Entre $7 \mathrm{~h}$ e $13 \mathrm{~h}$ & 224 & $62 \%$ & 268 & $61 \%$ & 245 & $64 \%$ & 259 & $63 \%$ & 236 & $65 \%$ & 214 & $65 \%$ \\
\hline Entre 13:01 e $19 \mathrm{~h}$ & 132 & $37 \%$ & 169 & $39 \%$ & 135 & $35 \%$ & 152 & $37 \%$ & 128 & $35 \%$ & 110 & $34 \%$ \\
\hline Após às 19h & 2 & $1 \%$ & 0 & $0 \%$ & 2 & $1 \%$ & 1 & $0 \%$ & 1 & $0 \%$ & 3 & $1 \%$ \\
\hline Total & 358 & $100 \%$ & 437 & $100 \%$ & 382 & $100 \%$ & 412 & $100 \%$ & 365 & $100 \%$ & 327 & $100 \%$ \\
\hline
\end{tabular}

Fonte: Dados da Pesquisa (2021)

Considerando as cirurgias realizadas nos 6 meses estudados, representam mais de $63 \%$ as cirurgias iniciadas entre as $7 \mathrm{~h}$ e $13 \mathrm{~h}$, enquanto as cirurgias da tarde simbolizam $36 \%$. Já o turno da noite, percebe-se que foi pouco utilizado, sem representação percentual sobre o total de cirurgias.

Posteriormente, foram analisadas algumas variações, como por exemplo, o Tempo de espera, encontrados pela diferença entre a hora da sala montada e o horário em que efetivamente a cirurgia começou, conforme detalha a Tabela 2 .

Tabela 2: Análise da base de dados

\begin{tabular}{rcccccc}
\hline Mês & $\begin{array}{c}\text { Quantidade } \\
\text { de Cirurgias } \\
\text { realizadas }\end{array}$ & $\begin{array}{c}\text { Tempo de } \\
\text { Espera (h) } \\
(*)\end{array}$ & $\begin{array}{c}\text { Tempo } \\
\text { Médio de } \\
\text { Espera por } \\
\text { Cirurgia (h) }\end{array}$ & $\begin{array}{c}\text { Duração da } \\
\text { Cirurgia (h) } \\
(*)\end{array}$ & $\begin{array}{c}\text { Tempo } \\
\text { Médio de } \\
\text { Cirurgia (h) }\end{array}$ & $\begin{array}{c}\text { \% Tempo de Espera / } \\
\text { Duração da Cirurgia (h) } \\
\mathbf{( * )}^{*}\end{array}$ \\
\hline jul/19 & 354 & $380: 15$ & $1: 04$ & $717: 14$ & $2: 01$ & 53,02 \\
ago/19 & 428 & $431: 50$ & $1: 00$ & $774: 54$ & $1: 48$ & 55,73 \\
set/19 & 374 & $510: 34$ & $1: 21$ & $680: 00$ & $1: 49$ & 75,08 \\
out/19 & 461 & $441: 44$ & $0: 57$ & $829: 02$ & $1: 47$ & 53,28 \\
nov/19 & 342 & $369: 42$ & $1: 04$ & $672: 27$ & $1: 57$ & 54,98 \\
dez/19 & 332 & $349: 58$ & $1: 03$ & $586: 51$ & $1: 46$ & 59,63 \\
& MÉDIA & $\mathbf{4 1 4 : 0 0}$ & $\mathbf{1 : 0 5}$ & $\mathbf{7 1 0 : 0 4}$ & $\mathbf{1 : 5 1}$ & $\mathbf{5 9 \%}$
\end{tabular}

$(*)$ Minutos no formato decimal Fonte: Dados da Pesquisa (2021)

Destaca-se que o Tempo de Espera para início da cirurgia é alto em todos os meses analisados, principalmente no mês de setembro, sinalizando $75 \%$ de atraso. Esse tempo representou, em todos os meses, mais de $50 \%$ de espera em relação aos tempos de cirurgias em si, como observado na coluna "\% Tempo de espera em relação a Duração da cirurgia".

o tempo médio de espera por cirurgia considerando os 6 meses foi de 01:05h, esse atraso acaba por ocultar a real capacidade do centro cirúrgico, caracterizando-se como a restrição do setor. Dentre os principais motivos que levam a esse alto Tempo de espera, destacam-se os mais frequentes que são os atrasos da equipe, a falta de material na hora programada e a checagem pré-operatória. 


\subsection{Mapa do estado atual}

Identificadas as fases de planejamento das cirurgias e os tempos encontrados na planilha de registro de cirurgias, foi desenhado o MFV para representar a situação atual do centro cirúrgico.

Para isso, primeiramente, foi utilizado o tempo médio de elaboração do mapa de programação de cirurgias, o tempo de admissão do paciente ao bloco cirúrgico e seu recebimento no pré-operatório, informados pela equipe do centro cirúrgico.

Os demais tempos foram provenientes da base de dados montada durante a pesquisa: média do "tempo de espera" (intervalo entre sala de cirurgia montada e início da cirurgia) e o "tempo médio de cirurgia" (intervalo entre início e término da cirurgia), ambos considerando o período de estudo.

\section{Figura 4 - MFV do estado atual}

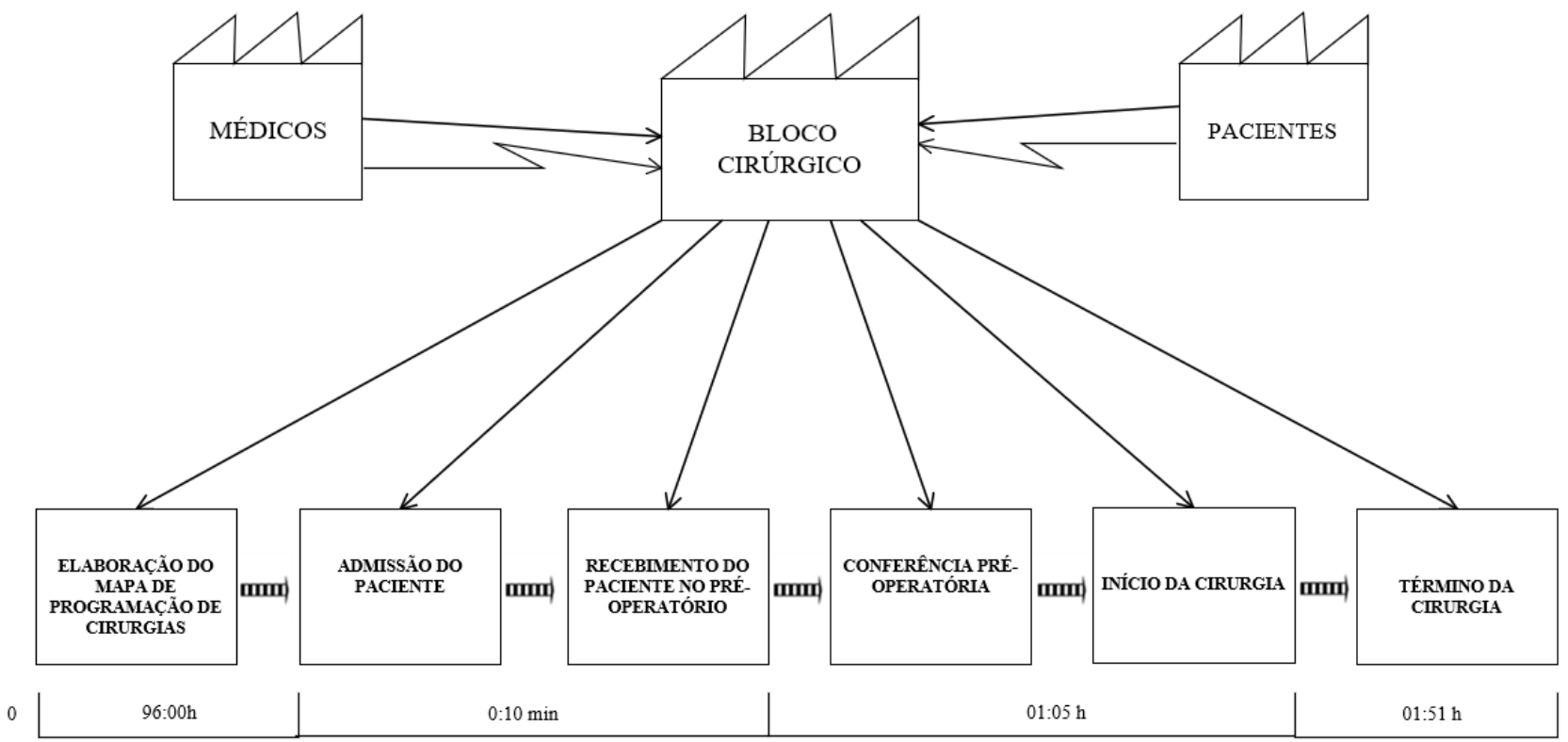

Fonte: Elaborado pelos autores (2021)

A primeira etapa dos trabalhos do centro cirúrgico consiste na elaboração do mapa de programação de cirurgias, que dura em média 96h (de quinta a domingo), considerando que os médicos têm até a quarta-feira para confirmar ao centro cirúrgico as cirurgias que vão realizar na semana subsequente.

A admissão do paciente ao bloco cirúrgico e recepção no pré-operatório geralmente ocorre em 10 minutos, pois os pacientes descem da enfermaria com antecedência. Quando os pacientes já estão no pré-operatório, a equipe realiza a checagem pré-operatória, verificando se há pendências em documentos/exames e confirmando se há disponibilidade de leitos de UTI ou de banco de sangue. Enquanto isso, o paciente aguarda no pré-operatório. Nesta etapa, não é incomum haver atrasos da equipe e de material, fatores que aditam nessa espera.

Com a análise do intervalo entre a "conferência pré-operatória" e o "início da cirurgia" foi verificada uma média de espera de 01:05h. Esse tempo de espera não agrega no resultado final, representando o gargalo do processo.

Já o intervalo médio entre o início e término das cirurgias, obtido por meio de média aritmética, resultou em 01:51h, considerados os vários tipos de cirurgia realizados (cirurgias ortopédicas; cardíacas; esofágicas; cranioplastias; cirurgias de hérnias; biópsias, entre outras).

\subsection{Aplicação do ORE (Operating Room Effectiveness)}

No intuito de avaliar o desempenho do centro cirúrgico foram utilizados preceitos do OEE como indicador base de eficiência produtiva, utilizando suas três vertentes principais: Disponibilidade, Performance e Qualidade.

Para o período estudado, será aplicada a metodologia proposta por Souza (2015) com a utilização do ORE ou "Eficácia da sala de operação", que nada mais é que um indicador com princípios da OEE adaptado para aplicação em centros cirúrgicos (Souza, Vaccaro \& Lima, 2020).

Souza (2015) demonstrou em seu estudo que assim como se apura o OEE, o ORE pode igualmente ser encontrado a partir do produto dos 3 indicadores (Disponibilidade, Desempenho e Qualidade).

Para aplicação do ORE foram utilizados os dados relativos aos meses de julho a dezembro de 
2019. Levantou-se que alguns profissionais cumprem jornada de 6 horas, outros de $12 \mathrm{~h}$, de modo que a todo momento existe equipe disponível no setor. Assim, foram considerados os plantões de $12 \mathrm{~h}$.

Após, foram levantadas as chamadas "Perdas de Eficiência", para cada indicador proposto pelo ORE. Ressalta-se que o ORE se utiliza dos mesmos indicadores da OEE, fazendo uma correspondência com as particularidades dos centros cirúrgicos, como mostra a Figura 5.

\section{Figura 5 - ORE e suas perdas}

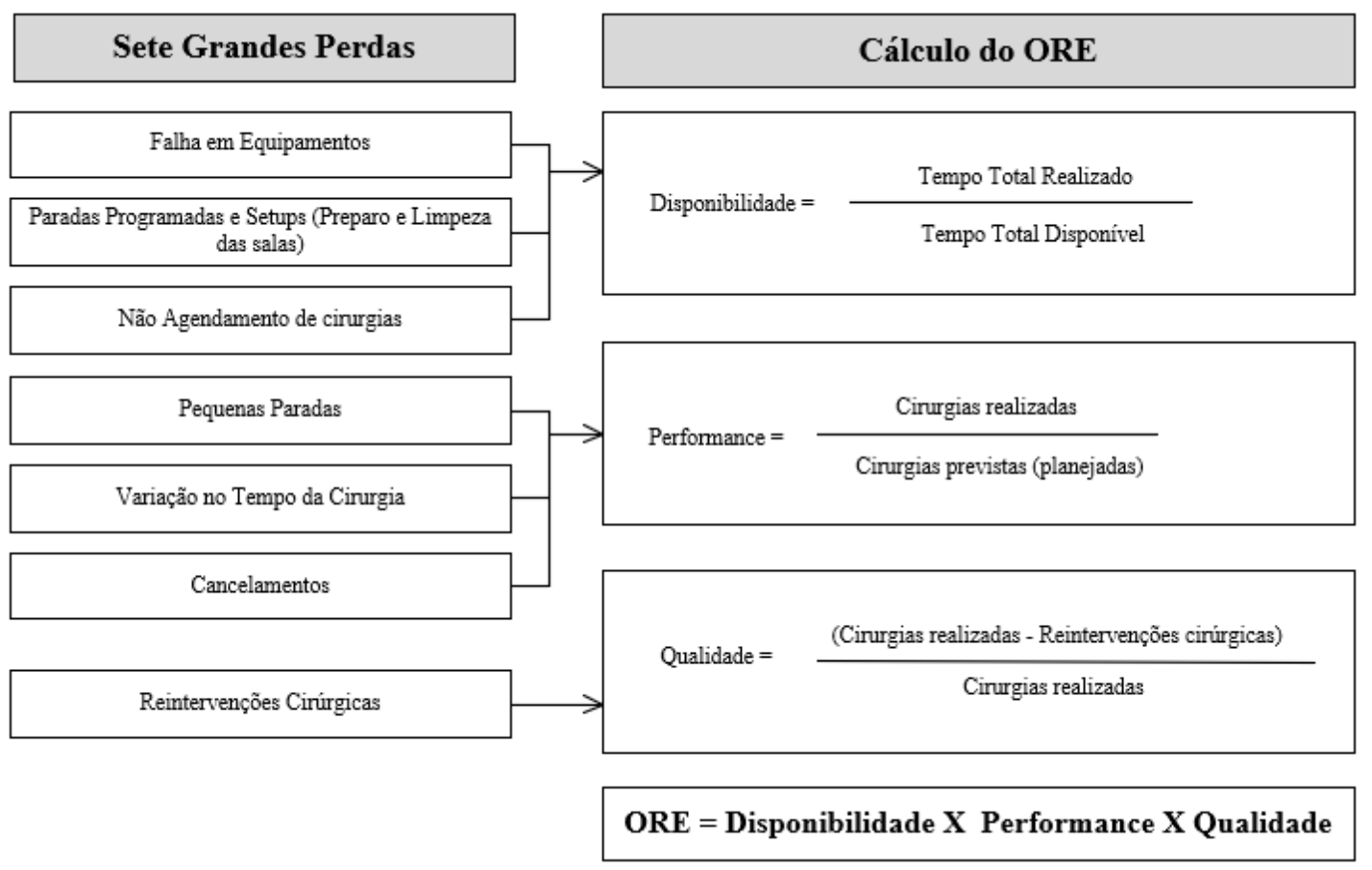

Fonte: Adaptado de Souza (2015)

\subsubsection{Disponibilidade}

Como perdas de Disponibilidade, Souza (2015) aponta as paradas para manutenção por falha de equipamentos, os setups e paradas programadas (como o tempo de montagem das salas e tempo de limpeza), e os não agendamentos de cirurgias, este último, caracterizado como momentos ociosos do setor.

Tendo em vista a indisponibilidade de alguns dados, para o cálculo do Tempo Total Disponível do período, primeiramente, considerou-se os 7 dias da semana como dias de trabalho no centro cirúrgico. Isso porque, os registros físicos apontaram plena atividade cirúrgica também aos finais de semana. Considerou-se ainda, o fato de o hospital universitário trabalhar em regime de plantões, onde, na teoria, todos os dias seriam passíveis de realizar operações.

Considerou-se ainda o tempo de disponibilidade do setor, que é de 24h. A Tabela 3 apresenta o cálculo realizado mês a mês.

Tabela 3 - Tempo total disponível do centro cirúrgico

\begin{tabular}{cccc}
\hline Mês & Dias de trabalho & Tempo Disponível (h) & $\begin{array}{c}\text { Tempo Total Disponível } \\
\text { (h) }\end{array}$ \\
\hline jul/19 & 31 & $24: 00$ & $744: 00$ \\
ago/19 & 31 & $24: 00$ & $744: 00$ \\
set/19 & 30 & $24: 00$ & $720: 00$ \\
out/19 & 31 & $24: 00$ & $744: 00$ \\
nov/19 & 30 & $24: 00$ & $720: 00$ \\
dez/19 & 31 & $24: 00$ & $744: 00$
\end{tabular}


Fonte: Dados da Pesquisa (2021)

A Tabela 3 apresenta o cálculo da capacidade máxima de horas disponíveis para cada um dos meses do período, que é o Tempo Total Disponível. Após, foram calculadas as perdas de disponibilidade. Tais perdas foram encontradas a partir da subtração entre a hora em que as salas já se encontravam montadas (prontas para cirurgia) e o horário em que efetivamente a cirurgia começou. Ou seja, foi o Tempo de Espera encontrado em cada mês.

Tabela 4 - Perdas de disponibilidade com tempo de espera

\begin{tabular}{lc}
\hline Mês & Tempo de espera (h) \\
\hline jul/19 & $380: 15$ \\
ago/19 & $431: 50$ \\
set/19 & $510: 34$ \\
out/19 & $441: 44$ \\
nov/19 & $369: 42$ \\
dez/19 & $349: 58$
\end{tabular}

Fonte: Dados da Pesquisa (2021)

Novamente, ressalta-se que não foi possível obter dados sobre os intervalos de tempo entre uma cirurgia e outra, que incluem a duração da limpeza ou setup das salas. Tais informações possibilitariam o cálculo da disponibilidade real do centro cirúrgico.

Sendo assim, o Tempo Total Realizado foi obtido a partir da diferença entre o Tempo Total Disponível, calculado na Tabela 3, e as Perdas de Disponibilidade obtidas na Tabela 4, portanto, tem-se:

Tabela 5: Cálculo do Indicador Disponibilidade

\begin{tabular}{rcccc}
\hline Mês & $\begin{array}{c}\text { Tempo Total } \\
\text { Disponível (h) }\end{array}$ & $\begin{array}{c}\text { Tempo de espera } \\
\text { (h) }\end{array}$ & $\begin{array}{c}\text { Tempo Total } \\
\text { Realizado (h) }\end{array}$ & \% Disponibilidade \\
\hline jul/19 & $744: 00$ & $380: 15$ & $363: 45$ & 48,89 \\
ago/19 & $744: 00$ & $431: 50$ & $312: 10$ & 41,96 \\
set/19 & $720: 00$ & $510: 34$ & $209: 26$ & 29,09 \\
out/19 & $744: 00$ & $441: 44$ & $302: 16$ & 40,63 \\
nov/19 & $720: 00$ & $369: 42$ & $350: 18$ & 48,65 \\
dez/19 & $744: 00$ & $349: 58$ & $394: 02$ & 52,96
\end{tabular}

Fonte: Dados da Pesquisa (2021)

A Tabela 5 apresenta os resultados para o índice Disponibilidade em cada mês da pesquisa, calculado pela relação entre Tempo Total Realizado / Tempo Total Disponível.

Sobre os percentuais de disponibilidade das salas, observa-se que apenas no mês de dezembro foi utilizado mais de $50 \%$ do Tempo Total Disponível, e que o mês de setembro teve o pior resultado no indicador. Grande parte do tempo perdido se deu por motivos de atrasos da equipe e de indisponibilidade de material no horário programado para a cirurgia.

Com os dados mensais, foi possível obter a média do índice de Disponibilidade do período de $43,70 \%$, evidenciando muitas perdas devido a não utilização do tempo total dos turnos de trabalho.

\subsubsection{Desempenho}

O Indicador Desempenho diz respeito a produtividade do setor, nesse sentido, Souza (2015) o descreve como a parte do Tempo Total Realizado que não é perdida com variações sobre a programação feita anteriormente. Assim, para o cálculo do desempenho leva-se em consideração:

- As variações com pequenas paradas, sejam elas com materiais da cirurgia, problemas nos 
equipamentos ou mesmo falta de energia repentina;

- As variações no tempo planejado para as cirurgias;

- E os cancelamentos de cirurgia.

Os dados do centro cirúrgico não foram suficientes para o computo das variações por pequenas paradas e no tempo planejado para as cirurgias. Assim, as perdas de desempenho foram encontradas subtraindo da previsão inicial de cirurgias o número de pacientes operados. A diferença entre cirurgias planejadas e realizadas se traduz nos cancelamentos. As perdas e os índices mensais de Desempenho calculados são expostos na Tabela 6 .

\section{Tabela 6 - Cálculo do indicador desempenho}

\begin{tabular}{rcccc}
\hline Mês & $\begin{array}{c}\text { Cirurgias } \\
\text { planejadas }\end{array}$ & Cirurgias realizadas & $\begin{array}{c}\text { Cancelamento } \\
\text { s }\end{array}$ & \% Desempenho \\
\hline jul/19 & 407 & 354 & 53 & 86,98 \\
ago/19 & 491 & 428 & 63 & 87,17 \\
set/19 & 432 & 374 & 58 & 86,57 \\
out/19 & 539 & 461 & 78 & 85,53 \\
nov/19 & 402 & 342 & 60 & 85,07 \\
dez/19 & 392 & 332 & 60 & 84,69
\end{tabular}

Fonte: Dados da Pesquisa (2021)

Os índices de desempenho foram calculados a partir da relação entre cirurgias realizadas e planejadas. Com 86,98\% o mês de julho foi o que apresentou o melhor desempenho, enquanto dezembro teve o menor percentual, de $84,69 \%$, sendo o número de cancelamentos os grandes responsáveis pela baixa performance.

No período do estudo, o número de cancelamentos foi de 372 , representando a média de $14 \%$ de cirurgias canceladas frente às programadas para o mesmo período. Os principais motivos de cancelamentos no período são evidenciados na Tabela 7.

Tabela 7 - Número e motivos de cancelamento de cirurgias

\begin{tabular}{|c|c|c|c|}
\hline Motivo do Cancelamento & $\mathbf{n}$ & $\begin{array}{c}\% \\
\text { unitário }\end{array}$ & $\begin{array}{c}\% \\
\text { acumulado }\end{array}$ \\
\hline \multicolumn{4}{|l|}{ Motivos hospital: } \\
\hline \multicolumn{4}{|l|}{ Falta de leito de CTI; falta de exames; cirurgião não compareceu; marcação errada; } \\
\hline \multicolumn{4}{|l|}{ preceptor doente; paciente sem indicação cirúrgica; falta de sala; priorização de } \\
\hline outra cirurgia; falta de circulante; indisponibilidade do cirurgião; alteração na & 156 & $42 \%$ & $42 \%$ \\
\hline \multicolumn{4}{|l|}{ Motivos Paciente: } \\
\hline \multicolumn{4}{|l|}{ Sem condições clínicas: Pressão alta; infecções; quadro clínico grave. } \\
\hline \multicolumn{4}{|l|}{ Outros motivos Paciente: } \\
\hline \multicolumn{4}{|l|}{ Uso de cigarro; AAS; se alimentou; não compareceu ou rejeitou a cirurgia. } \\
\hline \multicolumn{4}{|l|}{ Outros motivos hospital: } \\
\hline Falta de material, equipamento ou por manutenção do setor de infraestrutura & 38 & $10 \%$ & $94 \%$ \\
\hline \multicolumn{4}{|l|}{ Outros motivos: } \\
\hline TOTAL & 372 & $100 \%$ & \\
\hline
\end{tabular}


Fonte: Dados da Pesquisa (2021)

Representando 42\% do total de casos de cancelamentos em 2019 estão os denominados "Motivos hospital", sendo aqueles em que o fato gerador do cancelamento foi desencadeado pela própria unidade ou adjacentes. Com $31 \%$ estão os motivos relacionados às Condições Clínicas do Paciente, ou seja, os sintomas físicos e ao quadro clínico. Entre esses fatores estão a pressão alta, alguma infecção, ou outros relativos ao perfil clínico avançado da doença. Verifica-se ainda que 11\% representam os cancelamentos igualmente ligados aos pacientes, mas por motivo de: uso de AAS; ter se alimentado ou fumado; positivo no Beta HCG; não comparecimento, não se internou, recusou o procedimento ou faleceu.

Motivos relacionados a materiais, equipamentos ou por necessidade de manutenções foram agrupados em separado e equivalem a $10 \%$ dos casos. São eles: falta de material; outros equipamentos com defeito; sem tomografia no hospital; falta de material OPME, necessidade de manutenção de equipamentos. A Falta de Tempo representou $6 \%$ dos cancelamentos e se relaciona a fatos inesperados que acontecem durante uma cirurgia que atrasam seu término e inviabilizam a realização da próxima.

Nota-se que as ocorrências mais reincidentes foram por motivos do próprio hospital e do paciente, ou seja, dizem respeito à equipe do centro cirúrgico ou setores ligados a ele, e a fatores associados às condições clínicas dos pacientes, o que representou $73 \%$ dos problemas de cancelamentos do setor.

\subsubsection{Qualidade}

0 indicador Qualidade, como o nome diz, diz respeito à qualidade do serviço prestado pelo centro cirúrgico, e suas perdas estão relacionadas às reintervenções cirúrgicas. 0 setor não realiza tais registros, o que inviabilizou o cálculo deste indicador. Portanto, neste estudo será atribuído 100\% ao indicador qualidade.

\subsection{Cálculo do Operating Room Effectiveness - ORE}

Como visto, o indicador ORE é obtido pelo produto dos indicadores Disponibilidade, Desempenho e Qualidade. Uma vez levantados os valores destes 3 indicadores, a Tabela 8 mostra o resultado encontrado no centro cirúrgico para o ORE.

\section{Tabela 8 - Cálculo ORE}

\begin{tabular}{ccccc} 
Mês & \% Disponibilidade & \% Desempenho & \% Qualidade & \% ORE \\
\hline jul/19 & 48,89 & 86,98 & 100 & 42,53 \\
ago/19 & 41,96 & 87,17 & 100 & 36,57 \\
set/19 & 29,09 & 86,57 & 100 & 25,18 \\
out/19 & 40,63 & 85,53 & 100 & 34,75 \\
nov/19 & 48,65 & 85,07 & 100 & 41,39 \\
dez/19 & 52,96 & 84,69 & 100 & 44,85 \\
MÉDIA & $\mathbf{4 3 , 7 0}$ & $\mathbf{8 6 , 0 0}$ & $\mathbf{1 0 0}$ & $\mathbf{3 7 , 5 8}$
\end{tabular}

Fonte: Dados da Pesquisa (2021)

Como apresenta na Tabela 8, o Gráfico 1 ilustra como melhor resultado o índice de eficiência de $44,85 \%$, obtido no mês de dezembro/19, enquanto o pior foi o mês de setembro, com $25,18 \%$. Assim, a eficiência média do centro cirúrgico apurada nos 6 meses, foi de 37,58\%, demonstrando pouco mais de $62 \%$ de perdas de eficiência no setor.

Nota-se que o média ORE do centro cirúrgico, de 37,58\%, está bem abaixo do que preconiza Nakajima (1989) e Hansen (2006) como desejável para o OEE, que consideram o índice de 85\% em diante como indicador de classe mundial.

\subsection{Propostas de melhorias}

Diante dos baixos índices apresentados principalmente no indicador Disponibilidade, verificou-se que o resultado do ORE do centro cirúrgico está bem deficiente frente ao índice ideal. Como o objetivo do 
indicador utilizado é concentrar as ações nas melhorias de eficiência, há de se considerar uma análise dos fatores que deram causa as perdas.

\section{Gráfico 1 - ORE Mensal}

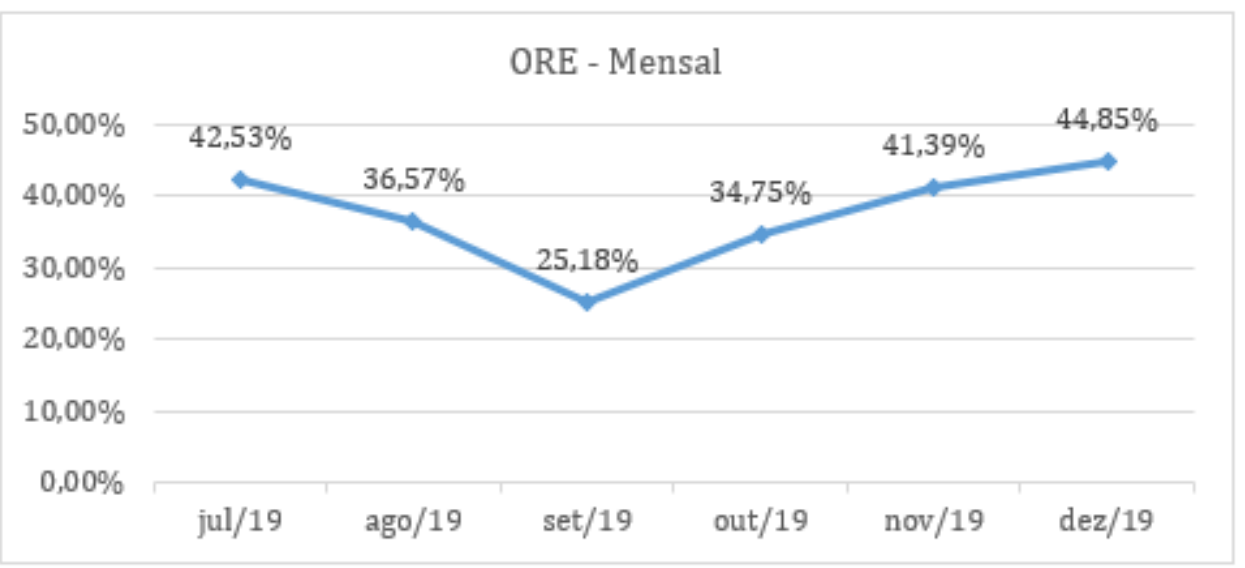

Fonte: Dados da Pesquisa (2021)

Como sugestão inicial, propõe-se unir a tecnologia ao planejamento do setor, onde todos os tempos do processo cirúrgico sejam mensurados utilizando planilhas eletrônicas, por meio da transferência periódica dos registros físicos. E que as planilhas registrem, rigorosamente, além de outros campos já existentes no livro:

- Data;

- Hora da sala montada;

- Hora de início e término da cirurgia;

- Hora de saída da sala de operação;

- Hora de Início e Término da limpeza ou setup.

- Hora de início e término de manutenção de equipamentos.

- Essas medidas possibilitariam o cálculo do indicador de disponibilidade mais próximo a realidade, a partir da mensuração das Perdas de Disponibilidade traduzidas em:

- Tempos de espera (Início da cirurgia menos Hora da sala montada);

- Duração da cirurgia (Início da cirurgia menos término da cirurgia);

- Permanência do paciente na sala após a operação (Saída da sala de operação - término da cirurgia);

- Duração da limpeza/setup (início da limpeza menos término da limpeza);

- Duração de paradas programadas para manutenção (hora do início da manutenção menos término da manutenção).

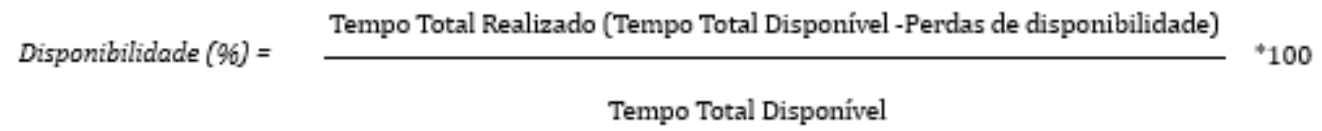

Para o cálculo da Performance/Desempenho, que sejam considerados os dados de pacientes operados em relação ao planejamento prévio de cirurgias, informações as quais o setor já dispõe.

$$
\text { Performance (96) }=\frac{\text { Produção real (cirurgias realizadas) }}{\text { Produção teórica (cirurgias planejadas) }} * 100
$$

Para o indicador de Qualidade, que o setor também passe a registrar eletronicamente as reintervenções cirúrgicas feitas para possibilitar tal cálculo.

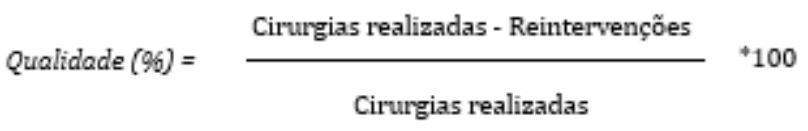

Adotar estas medidas e passar a acompanhar os resultados destes indicadores compõe uma 
gestão eficiente dos recursos. Assim, as falhas podem ser identificadas com mais rapidez, e melhor compreendidas pela equipe.

Sugestiona-se ainda, considerando a pouca utilização do turno noturno, aprimorar o gerenciamento dos turnos de trabalho, de modo a melhor aproveitar os horários de cada profissional.

Outra implementação de melhoria seria com base no alto tempo de espera para início das cirurgias. De forma análoga, a matéria-prima, que é o paciente, está demorando em média 01:05h a chegar na sala de operação, o que consequentemente, está atrasando toda a produção. A redução no tempo de espera reflete no aumento do índice de eficiência.

Ressalta-se que os hospitais universitários trabalham com cirurgias eletivas, onde cada passo pode ser planejado. Ademais, considerando o tempo de espera alto e passível de redução, foi realizada uma simulação que reduziu o tempo de espera de cada cirurgia em 10 minutos, em cada mês estudado.

Tabela 9 - Simulação cálculo da disponibilidade com redução do tempo de espera

\begin{tabular}{rcccc}
\hline Mês & $\begin{array}{c}\text { Tempo Total } \\
\text { Disponível (h) }\end{array}$ & $\begin{array}{c}\text { Tempo de espera (h) } \\
\text { (com redução de 10 min) }\end{array}$ & $\begin{array}{c}\text { Tempo Total } \\
\text { Realizado(h) }\end{array}$ & $\begin{array}{c}\text { \% } \\
\text { Disponibilidade }\end{array}$ \\
\hline jul/19 & $744: 00$ & $329: 27$ & $414: 33$ & 55,72 \\
ago/19 & $744: 00$ & $368: 28$ & $375: 32$ & 50,47 \\
set/19 & $720: 00$ & $449: 57$ & $270: 03$ & 37,51 \\
out/19 & $744: 00$ & $377: 16$ & $366: 44$ & 49,29 \\
nov/19 & $720: 00$ & $317: 40$ & $402: 20$ & 55,88 \\
dez/19 & $744: 00$ & $299: 07$ & $444: 53$ & 59,80 \\
& & & MÉDIA & $\mathbf{5 1 , 4 4}$
\end{tabular}

Fonte: Dados da Pesquisa (2021)

Com a simulação, a média percentual do indicador Disponibilidade aumentou cerca de $7 \%$, saindo de $43,70 \%$ para $51,44 \%$ nos 6 meses do estudo.

Outra sugestão se baseia nos números de cancelamentos cirúrgicos, responsáveis pela queda no desempenho do setor, mesmo este indicador tendo apresentado os melhores índices. Tais perdas devem ser discutidas, trabalhadas e reduzidas para produzir melhorias de eficiência.

Assim, dados os números de cancelamentos no período, foi realizada uma nova simulação, desta vez, reduzindo o número de cancelamentos em $30 \%$.

Tabela 10 - Simulação cálculo do Desempenho com redução no no de cancelamentos

\begin{tabular}{rccc}
\hline Mês & $\begin{array}{c}\text { Cirurgias realizadas } \\
\text { (com redução de 30\% } \\
\text { nos cancelamentos) }\end{array}$ & Cirurgias planejadas & \% Desempenho \\
\hline jul/19 & 370 & 407 & 91 \\
ago/19 & 447 & 491 & 91 \\
set/19 & 391 & 432 & 91 \\
out/19 & 484 & 539 & 90 \\
nov/19 & 360 & 402 & 90 \\
dez/19 & 350 & 392 & 89 \\
& & MÉDIA & $\mathbf{9 0}$ \\
\hline
\end{tabular}

Fonte: Dados da Pesquisa (2021) 
Com a nova simulação, a média percentual do indicador Performance aumentou 4\%, saindo de $86 \%$ para $90 \%$ no período da pesquisa.

Salienta-se que as simulações se tratam de opções ou hipóteses, sendo a decisão final cabível unicamente à equipe do centro cirúrgico mediante reuniões e análises ponderadas das causas de perdas de eficiência.

Desta feita, a Tabela 11 apresenta, por fim, os resultados das simulações para cada indicador e os respectivos aumentos no ORE se utilizado: apenas a redução no tempo de espera, apenas a redução no número de cancelamentos ou, se forem consideradas ambas as reduções.

Tabela 11 - Simulações e cálculo do ORE

\begin{tabular}{|cccccc} 
& $\begin{array}{c}\% \\
\text { Disponibilidade } \\
\text { (média) }\end{array}$ & $\begin{array}{c}\% \\
\text { Desempenho } \\
\text { (média) }\end{array}$ & $\begin{array}{c}\% \\
\text { Qualidade } \\
\text { (média) }\end{array}$ & $\begin{array}{c}\% \\
\text { ORE }\end{array}$ & $\begin{array}{c}\% \text { Variação } \\
\text { ORE ATUAL }\end{array}$ \\
\hline Simulações & S3,70 & 86,00 & 100,00 & 37,58 & - \\
\hline Redução de 10 min nos tempos de espera & 51,44 & 86,00 & 100,00 & 44,24 & 6,66 \\
\hline Redução de 30\% nos cancelamentos & 43,70 & 90,00 & 100,00 & 39,33 & 1,75 \\
\hline Redução de 10 min + Redução de 30\% & 51,44 & 90,00 & 100,00 & 46,30 & 8,71 \\
\hline
\end{tabular}

Fonte: Dados da Pesquisa (2021)

O Gráfico 2 ilustra o emprego das simulações e as alterações sofridas no indicador ORE.

\section{Gráfico 2 - Comparação ORE atual e simulações}

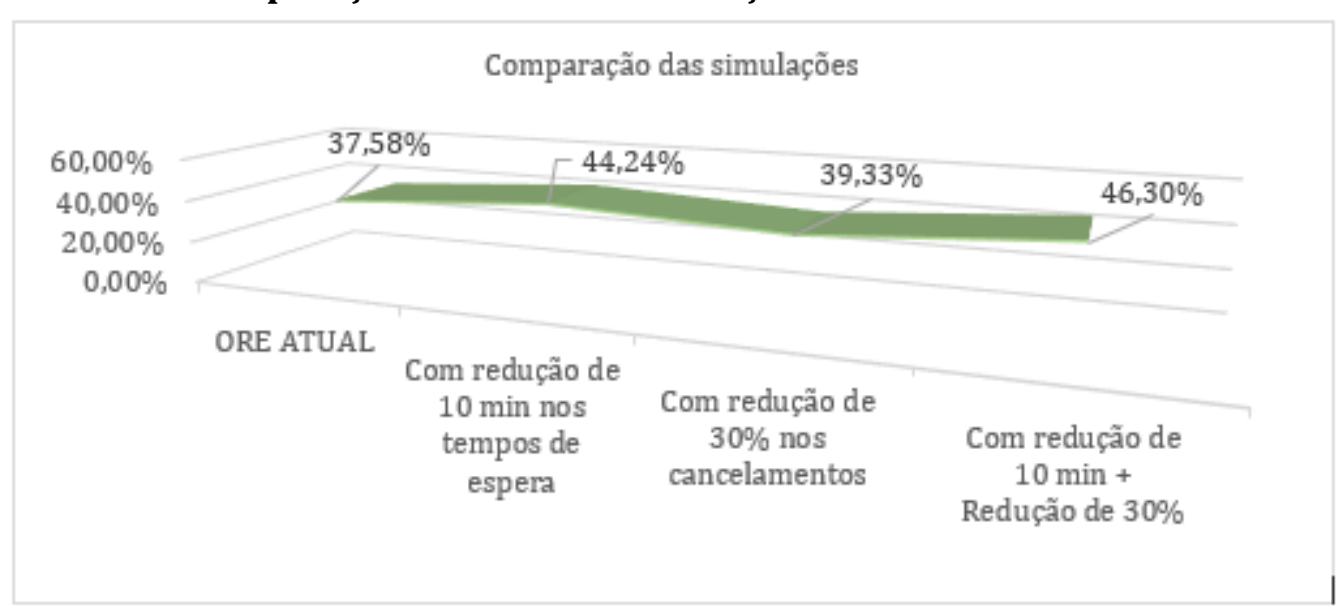

Fonte: Dados da Pesquisa (2021)

Ademais, o Gráfico 2 mostra resultados relevantes com a redução de10 minutos nos tempos de espera para início das cirurgias, com o índice de eficiência ORE atual aumentando 6,66\%, chegando a $44,24 \%$. E este, quando combinado à redução de cancelamentos em $30 \%$, o que representa um aumento de $8,71 \%$, passando a ter a eficiência de $46,30 \%$.

\section{Mapa do estado futuro}

A construção do Mapa futuro focou em melhorias na restrição do processo, que é o tempo de espera para o início das cirurgias. Com a simulação, sugestionou-se a redução desse tempo de espera em 10 minutos, com isso, o tempo médio de espera por cirurgia passou de 1:05h para 0:56 minutos.

A Figura 6 demonstra que é possível haver redução dos altos tempos de espera no processo desde que exista um plano de ação associado a um planejamento prévio específico. Como dito anteriormente, cabe a equipe do centro cirúrgico analisar e adotar um plano de ação exequível para mitigar essa restrição ao melhor tempo possível, seja reduzindo em 10 min, 20 min ou mais.

Verificou-se que as causas que motivaram a espera elevada incluem atrasos da equipe e falta de material no momento das cirurgias. Nesse sentido, um plano voltado a equipe que inclua, 
precipuamente, feedbacks aos colaboradores, pode ajudar a encontrar as causas dos atrasos. Nesse momento ouvir a equipe é importante, faz com que os colaboradores avaliem a situação geral e consequentemente se autoavaliem. Para o atraso de aparato material, torna-se relevante a gestão destes insumos.

\section{Figura 6 - MFV do estado futuro}

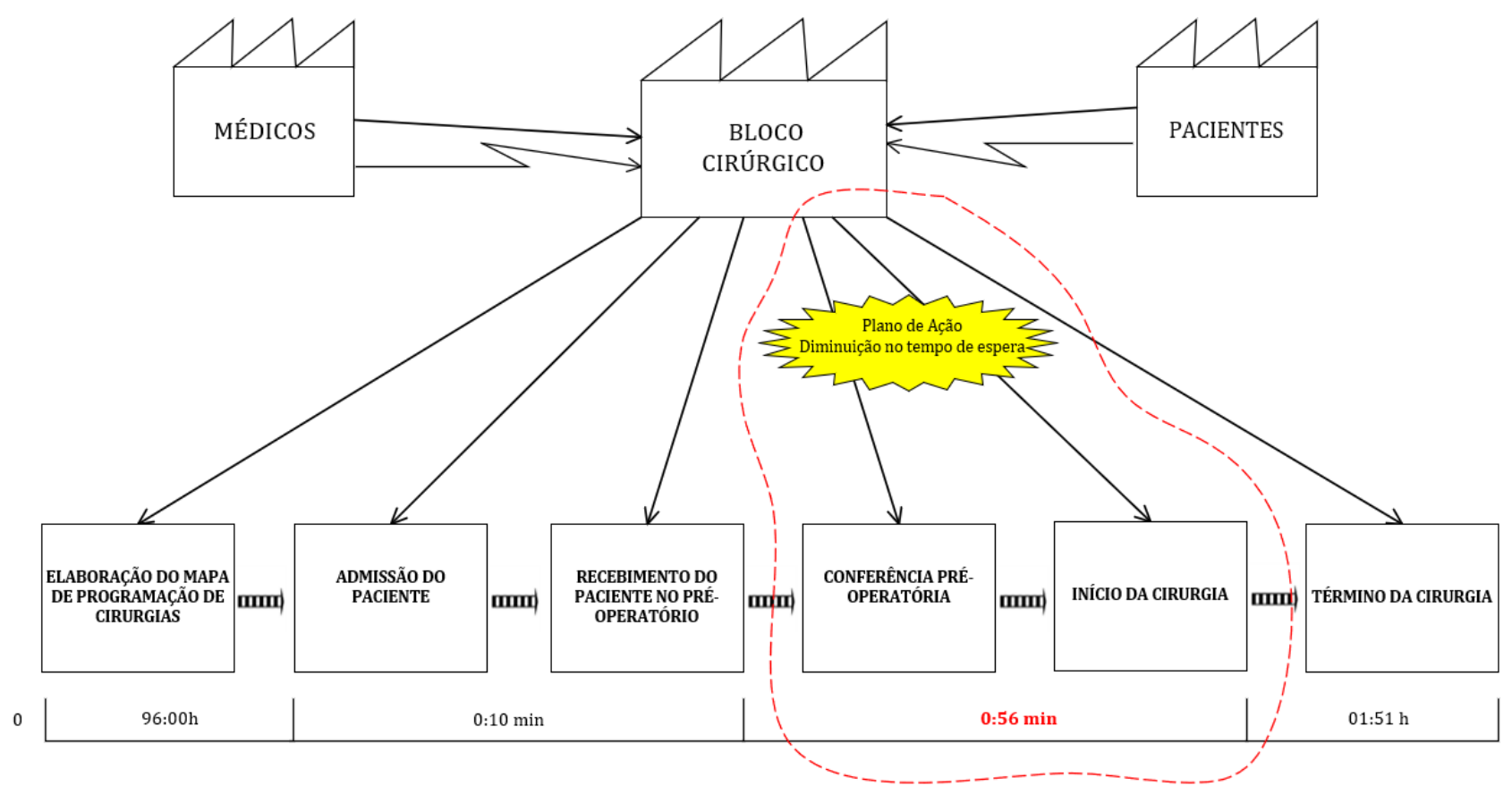

Fonte: Elaborado pelos autores (2021)

\section{Implicações teóricas e práticas}

Este estudo destaca o uso de indicadores para o gerenciamento das operações hospitalares e reforça a contribuição teórica de que os pressupostos da administração podem ser empregados nas mais diversas áreas trazendo ganhos gerenciais concretos.

Verificou-se que, como implicação prática, que os dados deste estudo colaboram com a parte operacional do centro cirúrgico, principalmente no tocante ao aprimoramento do processo atual. Desse modo, as informações da pesquisa podem auxiliar na qualificação do planejamento do setor, destacando os benefícios da otimização do tempo nos processos, aumentando, desta forma, a capacidade de procedimentos cirúrgicos do centro cirúrgico.

Acredita-se que uma gestão eficiente do tempo pode subsidiar um planejamento eficaz dos recursos e consequentemente, proporcionar maior oferta de atendimento a sociedade que demanda por cirurgias, o que representa um ganho social deveras relevante.

\section{Considerações finais}

O objetivo desse estudo foi apresentar uma proposta para avaliar o desempenho do Centro Cirúrgico de um Hospital Universitário baseada no OEE. O estudo de caso levantou dados dos meses de julho a dezembro de 2019, onde foi possível calcular o indicador de eficácia da sala de operação - ORE.

A avaliação apresentou um índice de eficiência do setor de 37,58\%, visto como deficiente em relação aos indicadores de classe mundial que condicionam índices inferiores a $65 \%$ a necessidade imediata de replanejar os processos.

Ficou demonstrado que a eficiência do centro cirúrgico sofre constante influência das perdas de disponibilidade com o não aproveitamento do tempo disponível para o trabalho; perda de tempo nos processos, além das perdas de produtividade devido ao número de cancelamentos cirúrgicos.

Nesse sentido, destaca-se o principal fator limitante ao processo cirúrgico, que são os expressivos tempos de espera para início da cirurgia, que duram em média, 1:05 hora. Visando evitar essas perdas no fator Disponibilidade, considera-se tratar as causas que impactam na espera já descritas anteriormente: os atrasos da equipe e a falta de material no momento da operação. Evitar essas reincidências são primordiais para aumentar os índices de disponibilidade das salas de operação, e consequentemente elevar o indicador de eficiência ORE.

Sendo assim, cabe aos gestores identificar e controlar a origem desses atrasos. A comunicação 
torna-se fundamental entre as equipes envolvidas para o controle dos recursos humanos e materiais.

No indicador Desempenho, que engloba sobretudo os cancelamentos de cirurgias, algumas ações primárias podem ser adotadas como revisar suas principais causas. Como visto, $42 \%$ dos cancelamentos se deram por motivos do próprio hospital, entre eles: Falta de leito de CTI; Falta de exames ou Pendências de pareceres documentais de outra especialidade. Puxar o planejamento para trás (fase pré-cirúrgica com check-list, reuniões pontuais, treinamentos), traçando estratégias com os outros setores envolvidos pode diminuir consideravelmente essas perdas.

Destaca-se como contribuição do estudo as simulações com sugestões de redução de tempos de espera e no número de cancelamentos, que evidenciaram ganhos de 8,71\% no ORE atual, aumentando o índice de eficiência para $46,30 \%$, além de sugestionar um melhor gerenciamento dos turnos de trabalho após as $19 \mathrm{~h}$, que hoje representam $1 \%$ do total de cirurgias realizadas, demonstrando subaproveitamento.

\section{Referências}

Alkaabi, M., Simsekler, M. C. E., Jayaraman, R., Al Kaf, A., Ghalib, H., Quraini, D., ... \& Demirli, K. (2020). Evaluation of System Modelling Techniques for Waste Identification in Lean Healthcare Applications. Risk Management and Healthcare Policy, 13, 3235.

Barrios, W. D., Nicodemo, D., Suzuki, V. Y., Sobral, C. S., \& Ferreira, L. M. (2020). Gestão de indicadores como ferramenta de educação continuada em serviços de nutrição hospitalar. Brazilian Journal of Development, 6(12), 103207-103217.

Bittar, O. J. N. V. (1996). Produtividade em hospitais de acordo com alguns indicadores hospitalares. Revista de Saúde Pública, 30, 53-60.

Chizzotti, A. (2018). Pesquisa em ciências humanas e sociais. Cortez editora.

Cima, R. R., Brown, M. J., Hebl, J. R., Moore, R., Rogers, J. C., Kollengode, A., ... \& Team, S. P. I. (2011). Use of Lean and six sigma methodology to improve operating room efficiency in a high-volume tertiarycare academic medical center. Journal of the American College of Surgeons, 213(1), 83-92.

Cooper, D. R., \& Schindler, P. S. (2016). Métodos de Pesquisa em Administração-12a edição. McGraw Hill Brasil.

Costa, L. B. M., \& Godinho Filho, M. (2016). Lean healthcare: review, classification and analysis of literature. Production Planning \& Control, 27(10), 823-836.

Da Silva, A., Ramos, S. P., Kroenke, A., \& Hein, N. (2019). Análise exploratória de indicadores de desempenho. RACE-Revista de Administração, Contabilidade e Economia, 18(1), 157-176.

Francischini, A. S., \& Francischini, P. G. (2018). Indicadores de Desempenho: Dos objetivos à açãométodos para elabora KPIs e obter resultados. Alta Books Editora.

Fitria, L., Dery, B. A., \& Prassetiyo, H. (2019). Implementasi lean healthcare untuk mengidentifikasi dan meminimasi waste di instalasi rawat jalan rsai bandung. Spektrum Industri, 17(2), 179-189.

Guimarães, L. M. (2018). Análise de eficiência de um centro cirúrgico hospitalar com abordagem do Lean Healthcare.

Hallam, C. R., \& Contreras, C. (2018). Lean healthcare: scale, scope and sustainability. International journal of health care quality assurance.

Hansen, R. C. (2006). Eficiência global dos equipamentos: uma poderosa ferramenta de produção/ manutenção para o aumento dos lucros. Porto Bookman, Alegre.

Klemann, P. P., Leal, I. M. S., Junior, C. A. F., Neves, R. M. D., \& DUARTE, A. A. A. M. (2020). A avaliação dos fatores determinantes para o aumento da produtividade em uma empresa produtora de dendê. The Journal of Engineering and Exact Sciences, 6(3), 0320-0325.

Lacerda, A. P., Xambre, A. R., \& Alvelos, H. M. (2016). Applying Value Stream Mapping to eliminate waste: a case study of an original equipment manufacturer for the automotive industry. International Journal of Production Research, 54(6), 1708-1720.

Miname $^{1}$, T. L., Martins, Y. A., Leonel, G. M., \& de Assis, M. A. (2017). Implantação de indicadores assistenciais em um serviço de enfermagem.

Nakajima, S., Conforti, M., \& Rubbia, S. (1997). TPM: total productive maintenance. Isedi.

Prodanov, C. C., \& de Freitas, E. C. (2013). Metodologia do trabalho científico: métodos e técnicas da pesquisa e do trabalho acadêmico-2 $2^{\text {a }}$ Edição. Editora Feevale.

Ramaswamy, R., Rothschild, C., Alabi, F., Wachira, E., Muigai, F., \& Pearson, N. (2017). Using Value Stream Mapping to improve quality of care in low-resource facility settings. International Journal for Quality in Health Care, 1-5.

Rocha, A. (2019). Pesquisa ação: educação em saúde pública veterinária dentro do conceito One Health em comunidades menos favorecidas (Doctoral dissertation, Universidade de São Paulo).

Rocha, A. L. S. da, \& Gonçalves, A. T. P. (2018). Aplicação de análise fatorial em indicadores de produtividade de identificação em uma empresa de indústria cerâmica vermelha. Revista Produção $e$ 
Desenvolvimento, 4(2), 92-110.

Rother, M., \& Shook, J. (2003). Learning to see: value stream mapping to add value and eliminate muda. Lean Enterprise Institute.

Saleem, F., Nisar, S., Khan, M. A., Khan, S. Z., \& Sheikh, M. A. (2017). Overall equipment effectiveness of tyre curing press: a case study. Journal of quality in maintenance engineering.

Severino, A. J. (2017). Metodologia do trabalho científico. Cortez editora.

Silva, F. A.da, \& Borsato, M. (2017). Organizational performance and indicators: Trends and opportunities. Procedia manufacturing, 11, 1925-1932.

Singh, P. (2019). Lean in healthcare organization: an opportunity for environmental sustainability. Benchmarking: An international journal.

Souza, P. C. D., Scatena, J. H. G., \& Kehrig, R. T. (2016). Aplicação da Análise Envoltória de Dados para avaliar a eficiência de hospitais do SUS em Mato Grosso. Physis: Revista de Saúde Coletiva, 26, 289-308.

Souza, T. A. (2015). Lean healthcare: aplicação dos conceitos de gestão de operações em centros cirúrgicos.

Souza, T. A., Vaccaro, G. L. R., \& Lima, R. M. (2020). Operating room effectiveness: a lean health-care performance indicator. International Journal of Lean Six Sigma.

Stadnicka, D., \& Litwin, P. (2019). Value stream mapping and system dynamics integration for manufacturing line modelling and analysis. International Journal of Production Economics, 208, 400-411.

Tlapa, D., Zepeda-Lugo, C. A., Tortorella, G. L., Baez-Lopez, Y. A., Limon-Romero, J., Alvarado-Iniesta, A., \& Rodriguez-Borbon, M. I. (2020). Effects of lean healthcare on patient flow: a systematic review. Value in Health, 23(2), 260-273.

Toledo, B. P., Ferrão, A. V., \& da Costa Cruz, M. M. (2019, August). Análise do Overall Equipment Effectiveness (OEE) para o equipamento convertedor em uma empresa de siderurgia. In Simpósio de Engenharia de Produção.

Tortorella, G., van Dun, D. H., \& de Almeida, A. G. (2019). Leadership behaviors during lean healthcare implementation: a review and longitudinal study. Journal of manufacturing technology management.

Tsarouhas, P. (2019). Improving operation of the croissant production line through overall equipment effectiveness (OEE). International journal of productivity and performance management.

Vignochi, L., Gonçalo, C. R., \& ROJAS LEZANA, Á. G. (2014). Como gestores hospitalares utilizam indicadores de desempenho?. Revista de Administração de Empresas, 54(5), 496-509.

Vilventhan, A., Ram, V. G., \& Sugumaran, S. (2019). Value stream mapping for identification and assessment of material waste in construction: A case study. Waste Management \& Research, 37(8), 815-825.

Yin, R. K. (2015). Estudo de Caso-: Planejamento e métodos. Bookman editora.

Zahrotun, N., \& Taufiq, I. (2018). Lean Manufacturing: Waste Reduction Using Value Stream Mapping. In E3S Web of Conferences (Vol. 73, p. 07010). EDP Sciences.

Zeferino, E. B. B., Sarantopoulos, A., Spagnol, G. S., Min, L. L., \& Freitas, M. I. P. D. (2019). Mapa de Fluxo de Valor: aplicação e resultados na central de desinfecção. Revista Brasileira de Enfermagem, 72(1), 140-146.

Zakaria, N. H., Mohamed, N. M. Z. N., Ab Rahid, M. F. F., \& Rose, A. N. M. (2017). Lean manufacturing implementation in reducing waste for electronic assembly line. In MATEC Web of Conferences (Vol. 90, p. 01048). EDP Sciences. 